\title{
Gloomy prospects for Britain's involvement in CERN research
}

\section{London}

ProsPECTS look grim for the high-energy physics community in Britain. According to physicists at a meeting in Geneva last week, a forthcoming report by Professor Anatole Abragam, of the Collège de France, will not meet British demands for substantial cuts in the budget of CERN, the European Organization for Nuclear Research. As a result, Britain may announce at the December meeting of the CERN council its intention of withdrawing from CERN in 1989.

In 1985 an inquiry commissioned by the British Science and Engineering Research Council (SERC) and the Advisory Board for the Research Councils (ABRC) and chaired by Sir John Kendrew proposed that Britain's membership of CERN should continue beyond 1989 only if it could do so "at a significantly lower cost". To achieve the necessary 25 per cent reduction by 1991 would require drastic cuts in the CERN programme, a new way of sharing the costs or the virtual abandonment of British experiments. None of these is reasonably possible.

SERC has already reduced its commitment to high-energy physics in response to pressure from other subject areas. An early victim of these cuts was the European Muon Collaboration at CERN which folded when the British contingent withdrew a year before the project was due to finish. According to Professor George Kalmus, director of the high-energy physics division of SERC's Rutherford Appleton Laboratory, Britain is missing out on some good physics. But the 'domestic' budget for high-energy physics has been shrinking faster than the 5 per cent per annum Kendrew recommends Britain now concentrates on projects at the proton-antiproton and Large ElectronPositron (LEP) colliders at CERN and HERA at DESY in West Germany.

Out of the total cost of high-energy physics in Britain of about $£ 75$ million this year, $£ 58$ million is the subscription to CERN. Spain's recently renewed membership and the prospective membership of Finland will do little to spread the cost of CERN. France and Switzerland have already rejected the use of a 'host's premium', as was proposed when the LEP project was initiated, to offset the purported benefits of having CERN sited in their territories. (They did, however, make additional material and financial contributions.)

Each member's subscription is based on its gross national product and costed in Swiss francs. The data used, however, are 5-8 years out of date. Although this has worked to Britain's disadvantage recently, the economic slump of the early 1980s will reduce Britain's future subscription. The weakening pound caused the 1987 subscription to jump from $£ 38 \mathrm{mil}$ lion to $£ 58$ million. The Treasury is prepared to offset this additional cost for this year and next. Many at CERN think that SERC's budget should be permanently protected against currency fluctuations.

Nor are there any prospects of significant savings in CERN's budget, which is divided equally between materials and staffing. According to Herwig Schopper, director-general of CERN, there is "no possibility of saving money from the materials budget". Similarly, any savings from the cost of staff will not be apparent until well into the $1990 \mathrm{~s}$.

LEP, costing about SFr 1,200 million, has been built within a constant budget since 1981, and will cost SFr 80 million per annum to run when completed in 1989 out of a total budget of SFr 774 million (in 1987 prices). Furthermore, maintenance has been held over because of the fixed budget. That CERN has continued to run is a testament, according to some physicists, to the high standard of engineering at CERN (often derided as gold plating).

Any cuts in staff numbers will initially cost more not less. CERN has already embarked on a programme to slim down staff by 10 per cent by the year 2000 . The management was criticized in an interim report written by Professor Abragam, and Schopper accepts the criticisms. The interim report also called for the staff cuts to be accelerated, so that $300-500$ jobs should be lost within two years.

Schopper suggests that future construction projects, such as the proposed Large Hadron Collider that would occupy the LEP tunnel, should be financed separately. The period of growth for highenergy physics, he says, is over. Indeed,

\section{IMAGE UNAVAILABLE FOR COPYRIGHT REASONS}

A superconducting solenoid destined for the DELPHI experiment at the Large ElectronPositron collider at CERN. It started its tortuous journey from the Rutherford Appleton Laboratory near Oxford on Sunday 18 October. It is now waiting near Newbury, only 15 miles away, while highway, electrical and telecommunica tions engineers address the more important task of repairing Britain's utilities after the gales.

between 1975 and 1980 , the CERN budget was reduced by a quarter in real terms, and cuts "in other sciences are not resulting because of us". British scientists argue that rather than seeing the CERN budget in terms of SERC expenditure, it should be compared to the cost of an averagesized university, which similarly has an infrastructure to be maintained.

The consequences of Britain's withdrawal from CERN are unimaginable, says Schopper. Others suggest that the position of British scientists would be uncomfortable when cuts were being effected if Britain withdrew. One theoretician said the scientific loss would be greater than the financial loss. And before making a decision, Britain would do well to recall Mrs Thatcher's praise for CERN in 1982: "I think [it is] money well spent. The work will go on." Roland Pease

\section{Scientific computing centre in Heidelberg}

\section{Heidelberg}

THE University of Heidelberg has announced the creation of an Interdisciplinary Centre for Scientific Computing. The Land of Baden-Württemberg is expected to approve the project in November. If approved, the centre will bring in several computer scientists to join professors in the mathematics, chemistry, physics and biology departments whose research touches on computer-intensive problems.

The university is negotiating with IBM for the use of a vector-processing add-on for the existing IBM 3090 computer. Heidelberg mathematics professor Willi Jäger said that the centre will concentrate on the application of computers to problems such as gene sequencing, model- ling the creation of galaxies, and the chemistry of combustion. There is already a concentration of researchers in Heidelberg working on stochastic mathematical modelling. Finding collaborators in computer science is a strongly felt need in the Heidelberg basic science departments in part because the university has no department of computer science.

The University of Heidelberg is trying to follow the examples set by the Courant Institute in New York and the University of Utah, albeit on a smaller scale. With the founding of an interdisciplinary centre in this field, Heidelberg is helping to create a trend in West German institutions toward breaking down barriers between the traditional faculties.
Steven Dickman 